\title{
A study of facility and community phase management of children with Severe Acute Malnutrition at NRC in Central Gujarat
}

\author{
Pandya N. ${ }^{1}$, Mehta K.G. ${ }^{2}$ \\ ${ }^{1}$ Dr. Nimisha Pandya, Department of Pediatrics, GMERS Medical College, Gotri, Vadodara, India, ${ }^{2}$ Dr. Kedar G. Mehta, \\ Department of Preventive and Social Medicine, GMERS Medical College, Gotri, Vadodara, India.
}

Corresponding Author: Dr. Nimisha Pandya, Department of Pediatrics, GMERS Medical College, Gotri, Vadodara, India. E-mail: nimisha.pandya@hotmail.com

\begin{abstract}
Background: The burden of Severe Acute Malnutrition, Severe underweight, and stunting is $-29.4 \%, 15.1 \%$ and $15 \%$. The India National Family Health Survey (NFHS 3, 2006) states that 20\% of children under five in India are wasted, contributing to half of the global burden of malnutrition. SAMis responsible directly or indirectly for $35 \%$ of deaths among children under five years. Objective: The objective of this study was to assess the demographic and clinical profiles of patients with SAM, assess effectiveness of NRC with relation to short term outcome and to assess compliance with the program and weight gainat the end of 2 months. Methods: A retrospective study was conductedin children with SAM aged less than 5 years in the NRC at GMERS Medical College Vadodara. The study assessed all children for recovery and mortality at end of inpatient stay and at end of program at 60 days. The short-term outcomes were compared to the SPHERE standards 2011. Period of study was from January 2017 to December 2017. Variables assessed were gender, age at presentation, socio- economic criteria, co-morbidities, anthropometric criteria, mean weight gain and compliance with follow up. Inclusion criteria used were anthropometric and clinical criteria used for classification of SAM. Results: 143 patients between age of 2 months to five years were admitted with SAM. The gender distribution for male to female patients was 1.1:1. Majority of children were aged less than 2 years (78.3). 89.5\% childrenwere coming from families below poverty line and $38.5 \%$ were fully immunized for age. $72.7 \%$ patients satisfied both anthropometric criteria. Commonest co- morbidity associated with SAM was diarrhea $22.4 \%$, followed by lower respiratory tract infections $20.3 \%$. Severe anemia was observed in $9.1 \%$ of patients. Outcomes were successful discharge in $93.7 \%$, mortality in $2.1 \%$, and default in $4.2 \%$. $76.2 \%$ children showed weight gain at least $15 \%$ from baseline weight. Complete follow up (3 visits) was achieved in $57.3 \%$ patients. Conclusion: Majority of patients presenting with SAM were belonging to below poverty line families which suggests that improving the socio economic conditions will have a positive impact on reduction on the incidence of severe malnutrition. Complete follow up visits were achieved in only half of the patients. Education of parents regarding the implications of malnutrition on long term quality of life and positive reinforcement for follow up can ensure that successfully discharged children do not default.
\end{abstract}

Keywords: Severe acute malnutrition, NRC, Outcomes

\section{Introduction}

Severe Acute Malnutrition (SAM) is defined as a weight-for-height measurement of $<-3 \mathrm{SD}$, presence of bilateral pitting edema of nutritional origin, ormidupper-arm circumference of less than $115 \mathrm{~mm}$ in children age $1-5$ years [1]. It is alife threatening condition requiring urgent treatment. SAM is responsible directly or indirectly for one-third of deaths among children under five years. The global burden of Severe Acute Malnutrition, Severe underweight, and

Manuscript received: $4^{\text {th }}$ September 2018

Reviewed: $14^{\text {th }}$ September 2018

Author Corrected: $20^{\text {th }}$ September 2018

Accepted for Publication: $24^{\text {th }}$ September 2018 stunting is- $29.4 \%, 15.1 \%$ and $15.1 \%$ [2]. Malnutrition in children is highly prevalent in India. Emphasis is laid on management of children with SAM due to 9 times higher risk of mortality in these children with mortality being higher in children co infected with HIV. Decreasing child mortality and improving maternal health depends heavily on reducing malnutrition. Initially, focus wasto refer these children to the NRC to receive therapeutic diets along with medical care. The introduction of ready to use therapeutic foods (RUTF) allows management of SAM without complications and passing the appetite test, in the community [3]. The 
Case Report

India National Family Health Survey (NFHS 3, 2006) states that $20 \%$ of children under five in India are wasted, contributing to half of the global burden of malnutrition. The objective of this retrospective study was to assess the demographic and clinical profiles of patients with SAM, assess effectiveness of NRC with relation to short term outcome and to assess compliance with the program and weight gainat the end of 2 months.

In India, the inpatient model for treatment of severe acute malnutrition (SAM) as well as community-based management of acute malnutrition (CMAM) was adopted under Mission Balam Sukham in year 2012 [4].

NRCs and CMTCs are inpatient facilities to treat SAM childrenin tertiary care hospitals and community respectively. Children fulfilling criteria for SAM according to WHO criteria are admitted in NRC with counseling of mothers for proper feeding, medical management, and discharged after completion of required NRC stay and requisite weight gain.

Management is done based on WHO and IAP guidelines for malnutrition. 3 follow up visits are done post discharge. The SPHERE project sets minimum standards in management of children with severe acute malnutrition, i.e. proportion of those who have recovered should be $>75 \%$, death should be $<10 \%$ and defaulted is $<15 \%[5]$. Recent study that is a compilation of information from five different studies on the efficacy of inpatient management of acute malnutrition in India reveals that the recovery rates of SAM children attending the inpatient facilities are still low and the defaulter rate is high when compared to the acceptable minimum standard.

The recovery rate varies widely in India from state to state and can be as low as $37 \%$. In all the studies, the recovery rate was well below the $75 \%$ standard set by SPHERE for intervention in children with SAM. All patients with SAM admitted in NRC are treated with therapeutic food, F- 75and F-100 followed by energy dense foods and adequate wt gain is expected. The outcomes for facility based management are good but the child falters in the community based phase as it returns to the same environment where optimal care is compromised.

Therefore the program provides for support till 60 days in form of 3 reimbursed follow up visits, micronutrients and RUTF (in some states), butlittle is known about the long-term sustainability of the nutritional and health benefits of treatment after rehabilitation.

\section{Objectives}

1. To assess the demographic and clinical profile of patients with SAM.

2. To assess the short term outcomes in form of successful discharge, mortality effective weight gain and to assess compliance with the program and weight gainat the end of 2 months.

\section{Materials and Methods}

Study Design- Retrospective cohort study, hospital based.

Study Center- NRC at GMERS Medical College and General Hospital, Gotri, Vadodara, Gujarat.

Study Period- January 2017 to December 2017 (one year).

Study Population- Children aged under 5 years with SAM

Inclusion Criteria- The criteria for admission for inpatient treatment in NRC were as per WHO reference [3].

Infants less than 6 months: Infant is too weak or feeble to suckle effectively (independently of his/her weight-for-length) or WFL (weight-for-length) $<-3$ SD (in infants $>45 \mathrm{~cm}$ ) or Visible severe wasting in infants. Children 6-59 months classified as SAM on basis of anthropometric and clinical criteria

1. WFH $<-3$ SD with or without any grade of edema. or

2. MUAC less than $11.5 \mathrm{~cm}$ or

3. Bilateral pitting edema

with Failure of Appetite Test

with associated complications:

1. Hypothermia.

2. Persistent vomiting

3. Lethargic, unconscious, convulsions

4. Hypoglycemia

5. Severe anemia $\mathrm{Hb}<4$

6. Sepsis

7. Extensive skin lesion

Exclusion criteria- children with SAM who refused for enrollment in NRC 


\section{Case Report}

Methodology- Children in age group of 0-5 years with SAM were enrolled after counseling parents regarding need forprolonged admission for 14 days. Patients were actively screened in community by Aanganwadi workers oractive screening was done during routine visit and illness in Pediatric OPD. All patients were subjected to a thorough evaluation regarding cause of malnutrition, age, weight, height/length, MUAC, presence or absence of bilateral edema, appetite and medical complications.

We have 15 bedded NRC with separate kitchen and Toy room. Consultant pediatricians along with medical officers attend to medical complications andguide the nutritionist regarding nutritional rehabilitation. All children were managed according to the 10 point program with early stabilization followed by catch up growth and preparation for discharge.

Therapeutic nutrition was administered, F-75 and F100. Daily weight gain was monitored. Micronutrients were provided and appetite was assessed. Monetary assistance was provided to family as wage loss, Rs $200 /$ day. Outcome in form of successful discharge, default and death was recorded. Weight at the time of admission and discharge was recorded and average weight gain was calculated. Children were considered successfully discharged from the NRC when

1) The child had no signs of bilateral pitting edema, fever, and/or infection.

2) The child had completed all age appropriate immunizations.

3) The child was being fed $120-130 \mathrm{kcal} / \mathrm{kg}$ weight/day

4) Adequate weight gaini. e $15 \%$ of weight gain at presentation in a non - edematous child

5) The primary caregiver is confident to care for child at home $[3,5]$.

All patients were discharged after 14 days and called for 3 visits at 15 day intervals at 1 month, 1.5 month and 2 months respectively. Monetary compensation and micronutrients wereprovided at each visit.

Statistical Analysis-The data was entered into Microsoft excel spread sheet and descriptive statistical analyses was done by SPSS Software.

\section{Results}

Table-1: Demographic and Anthropometric profile of patients with severe acute malnutrition admitted in NRC $(\mathrm{N}=143)$.

\begin{tabular}{|c|c|c|c|}
\hline \multicolumn{2}{|c|}{} & Number & Percent \\
\hline \multirow{2}{*}{ Sex } & Male & 76 & $53.1 \%$ \\
\cline { 2 - 4 } & Female & 67 & $46.9 \%$ \\
\hline \multirow{2}{*}{ Age } & $<1$ year & 66 & $46.1 \%$ \\
\cline { 2 - 4 } & $1-2$ years & 46 & $32.2 \%$ \\
\cline { 2 - 4 } & $2-3$ years & 10 & $06.9 \%$ \\
\cline { 2 - 4 } & $3-4$ years & 12 & $08.4 \%$ \\
\hline \multirow{3}{*}{ Immunization } & $4-5$ years & 9 & $06.3 \%$ \\
\hline \multirow{2}{*}{ Socio economic status } & Complete & 58 & $38.5 \%$ \\
\hline \multirow{2}{*}{ Anthropometric criteria } & Partial & 128 & $81.5 \%$ \\
\cline { 2 - 4 } & Below poverty line & 15 & $10.5 \%$ \\
\cline { 2 - 4 } & Above poverty line & 104 & $72.7 \%$ \\
\hline
\end{tabular}

143 patients were evaluated. Median age of presentation was 14 months. $78.2 \%$ children were under 2 years of age which is statistically significant as compared to children between $2-5$ years of age ( $\mathrm{p}$ value $<0.5$ ). There was no statistical difference in gender distribution in SAM (M:F) 1.1:1. 88 SAM children were partially immunized for age (89.5\%) which was found to be statistically significant in comparison with completely immunized for age $(\mathrm{p}<0.05)$. Majority of the children 128(89.5\%) were from below poverty line families which was found to be statistically significant $(\mathrm{p}<0.05)$. Both anthropometric criteria were fulfilled in $72.7 \%$ patients. 
Table-2: Co morbidities in SAM patients admitted in NRC ( $N=143)$.

\begin{tabular}{|c|c|c|}
\hline Acute gastroenteritis & 32 & $22.4 \%$ \\
\hline Pneumonia & 29 & $20.3 \%$ \\
\hline Severe anemia & 13 & $09.1 \%$ \\
\hline Urinary tract infections & 12 & $08.4 \%$ \\
\hline Infantile tremor syndrome & 5 & $03.5 \%$ \\
\hline Tuberculosis & 6 & $04.2 \%$ \\
\hline Measles & 1 & $0.6 \%$ \\
\hline Congenital heart disease & 4 & $02.8 \%$ \\
\hline
\end{tabular}

Commonest co morbid condition observed was acute gastroenteritis $(22.4 \%)$, followed by pneumonia $(20.3 \%)$. Severe anemia and Urinary tract infections were observed in $09.1 \%$ and $08.4 \%$ children. One -third of children with SAM suffer from Pneumonia and one-third of children suffer from urinary tract infection. Therefore Chest X -ray and urine examination are mandatory for all children with SAM.

Table-3: Outcome of SAM patients admitted under nutritional rehabilitation program at NRC (N=143)

\begin{tabular}{|c|c|c|}
\hline Discharge & 134 & $93.7 \%$ \\
\hline Default & 06 & $04.2 \%$ \\
\hline Death & 03 & $02.1 \%$ \\
\hline Expected Weight gain 15\% of baseline & 109 & $76.2 \%$ \\
\hline 3 follow up visits done & 94 & $65.7 \%$ \\
\hline
\end{tabular}

\begin{tabular}{|c|c|c|}
\hline No. of Follow up visits & No. & Percentage \\
\hline 3 follow up visits & 94 & $65.7 \%$ \\
\hline 2 follow up visits & 23 & $16.1 \%$ \\
\hline 1 follow up visit & 7 & $04.9 \%$ \\
\hline Nil & 10 & $06.9 \%$ \\
\hline
\end{tabular}

93.7\% children were discharged with $76.2 \%$ children showing effective weight gain. The discharge, default and death rates are in accordance with SHERE Humanitarian standards. Complete Follow-up visits were achieved in 57.3\% patients only. Emphasis should be laid on follow-up visits.

09 children were excluded (3 deaths and 6 default). Average weight gain was $8.4 . \mathrm{gm} / \mathrm{kg} /$ day.

\section{Discussion}

143 patients were admitted in our NRC. Total NRC admissions contributed to $2.1 \%$ of all pediatric admissions. Prevalence of SAM is reported to vary in different studies in India from 3.6\% in Puducherryto national prevalence being $6.4 \%$ [6].

There was no statistical difference in sex distribution of admitted patients in our study. Some studies suggest a difference in sex distribution in children with SAM with a slight female predominance due to socio cultural factors. Other studies in Africa as well as India do not suggest a statistical difference [6-8].

In our study SAM was predominant in children less than 2 months to1 year and 1-2 years, (46.1\%) and $(32.2 \%)$ respectively. $80 \%$ children with SAM in study by Mathur et all were under 24 months[9]. 92.5\% of SAM children were under 24 months in study in
Nigeria. This is a reflection of poor feeding practices observed in the lower socio economic strata like poor exclusive breast feeding rates, improper complementary feeding practices and recurrent diarrhea and respiratory tract infections.

The median age of presentation was 14 months. The mean age of presentation is similar to other studies in India and Africaa [8-10]. Mean age was reported to be 22.3 months in Sudan and 14.8 months in Enugu, Nigeria[8].

$89.5 \%$ of patients with SAM were from families living below poverty line. Lesser association was observed in African studies (35.4\%) and in Bangladesh (64.9\%) [10]. Poor economic conditions have adirect impact on nutrition in form of reduced and poor quality of nutrients and limited access to health care. 


\section{Case Report}

Incomplete immunization was observed in $61.5 \%$ children in our study. $91 \%$ children with SAM were partially immunized in a study in Ibadan, Nigeria versus $66 \%$ in Sudan [7].

Partial immunization was also reported to be a risk factor for SAM in study in central India. Immunization is an indicator of health care and has role in prevention of malnutrition. The risk of malnutrition increases in incompletely immunized children due to increased risk of infections and late identification of growth faltering.

Commonest co morbid condition observed was gastroenteritis $32(22.4 \%)$ followed by pneumonia 29 $(20.3 \%)$. Studies in developing countries as well as different parts of India show similar results though African studies show significant presentation of Malaria due to the endemicity. This was corroborated in studies conducted at Nepal, central India and Rajasthan[11-13].

Discharge, default rate and death rate were 134 (93.7\%), 06 (04.2\%), 03(02.1\%) respectively.

These outcomes are in accordance with WHO objectives in effective management of SAM [3]. This proves that effective medical and therapeutic management can reduce the risk of mortality in children.

Average weight gain achieved was $8.4 \mathrm{gm} / \mathrm{kg} /$ day and $78 \%$ of children gained at least $15 \%$ from baseline weight.

\section{Conclusion}

Hence, we can conclude that Severe Acute Malnutrition is a problem that needs to be tackled aggressively. NRCs are well supported by the government. Strengthening of the rural health sector for immunization, active screening for common childhood illnesses as per IMNCI program can lead to early detection, arrest and correction of growth deceleration in our children.

Community management of SAM and introduction of RUTF is the next step that will reduce the prevalence of SAM in long run.

Recommendation- The outcomes of children with SAM admitted at the center were favourable as per the SPHERE standards. Continuous evaluation and strengthening of the NRCs with adequate human resources and infrastructure along with motivation of parents can sustain these outcomes.
The follow up rates of these children are poor. Parents need guidance and motivation by the local health workers to improve the follow up. Therefore a robust system of liasioning between the tertiarycare centres and peripheral health sector needs to be developed.

\section{Contribution}

- Dr Kedar Mehta :for statistical analysis and final drafting.

- Ms Hiral Patel :for data collection.

Funding: Nil, Conflict of interest: None initiated, Perission from IRB: Yes

\section{Acknowledgement}

\section{References}

1. Community-based management of severe acute malnutrition [Internet]. A joint statement by World Health Organization, the World Food Programme, the United Nations System Standing Committee on Nutrition and the United Nations Children's Fund. Geneva: World Health Organisation;2007

2. National Family Health Survey (NHFS-4). Ministry of Health and Family Welfare. 2015-2016. Availablefrom:URL:http://rchips.org/NFHS/pdf/NFHS 4 / India.pdf

3. WHO Guidelines Approved by the Guidelines Review Committee. Guideline: Updates onthe Management of Severe Acute Malnutrition in Infants and Children. children.vol.2013.Geneva, 2013.p.6-54..

4. SPHERE: Sphere project: humanitarian charter and minimum standards in disaster response . 2011.

5. Mission BalamSukham, Health and Family Welfare Department, Government of Gujarat. Available on www.gujhealth.gov.in/mission_balam_sukham.htm

6. Shewade HD, Sunderamurthy B, Jayakumar N, Ramadoss P. Prevalence of severe acute malnutrition (SAM) among under-five children: A community based cross-sectional study from Puducherry India. Indian Journal of Maternal and Child Health. 2013; 15 (1): [8] p.

7. Shaza OH, Mohammed OS. Prevalence and outcome of severe malnutrition in children less than five -year old in Omdurman Pediatric Hospital, Sudan. Sudanese Journal of Paediatrics. 2016; Vol 16(1):23-30. 


\section{Case Report}

8. Ubesei AC, Ibeziako NS, Ndiokwelu C, Uzoka CM, Nwafor CA. Under- five protein energy malnutrition admitted at the university of Nigeria Teaching Hospital, Enugu: a 10 year retrospective review. Nutrition Journal 2012;11:43-50.

9. Mathur A, Tahilramani G, Makhija S, Devgan V. Burden of Severe Acute Malnutrition in under-five Children (2-59 Months) Admitted in a Tertiary Care Hospital of Delhi. J Trop Pediatr. 2018 Feb 1;64(1): 45 50. doi: 10.1093/tropej/fmx026.

10. Nahar B, Ahmed T, Brown KH, Hossain MI. Risk Factors Associated with Severe Underweight among Young Children reporting to a Diarrhoea Treatment Facility in Bangladesh. Journal of Health Population and Nutrition October 2010; 28(5):476-483.
11. Mishra K, Kumar P, Basu S, Rai K, Aneja S. Risk factors for Severe Acute Malnutrition in children below five years of age in India: A case-control study. Indian Journal of Paediatrics. 2014 August; 81 (8): 762-5.

12. Thapa A, Shah GS, Mishra OP. Analysis of Comorbidities in Children with Severe Acute Malnutrition in Eastern Nepal. Journal of Nepal Paediatric Society 2015 May-August;35(2):9-102..

13. Saini DT, Verma DA, Berwal PK. Pattern of Comorbidities in Children with Severe Acute Malnutrition admitted in MTC of a teaching hospital of Western Rajasthan, India. J Med Science and Clinical Research. 2016 April;4(4):10070-73.

\section{How to cite this article?}

Pandya N, Mehta K.G. A study of facility and community phase management of children with Severe Acute Malnutrition at NRC in Central Gujarat. Int J Pediatr Res.2018;5(9):468-473. doi:10.17511/ijpr.2018.i09.07. 